\section{ARTICLE}

Peter Stam and Katy Long Office for National Statistics

\section{SUMMARY}

The duration of unemployment is an indicator of how efficient the labour market is at matching workers to jobs. Understanding the drivers of unemployment is of interest to policy makers, researchers and the public alike. Economic theory suggests that there will always be some measure of frictional unemployment in any economy, as it takes time for workers to search for and find appropriate jobs (ONS, 2008). This article analyses the effect that an individual's characteristics have on the length of their unemployment, and ultimately on their likelihood of becoming employed.

\title{
Explaining exits from unemployment in the UK, 2006-09
}

\section{Introduction}

$\Lambda$ ggregate estimates of unemployment by duration, age and sex are published by the Office for National Statistics (ONS) in the Labour Market Statistical Bulletin ${ }^{1}$. These are derived from individual responses to the Labour Force Survey (LFS). In 2009 ONS published evidence and analysis on the relationship between the length of an individual's spell of unemployment and the associated probability of leaving unemployment (Long, 2009). The study uses the British Household Panel Survey (BHPS) to analyse the factors that affect the length of unemployment spells. It estimates the probability of exiting unemployment finding that individuals are less likely to exit unemployment as the length of the spell increases (all other things being equal). Long (2009) also notes that the characteristics of the individual (such as education and housing situation) has a significant impact.

The objectives of this article are to test consistency between the LFS and BHPS data, to analyse the underlying factors which affect duration of unemployment, and to investigate the relationship between an individual's characteristics (including length of unemployment) and their employment prospects. This is achieved by using LFS data to model the probability of an individual having an unemployment spell. This model is extended to estimate the length of an individual's unemployment spell. Finally, the LFS model estimates the probability of finding employment, given the duration of unemployment and other characteristics. Another model is then estimated using BHPS data. This model estimates the probability of exiting unemployment to a specific destination, distinguishing between moving from unemployment to either employment or economic inactivity.

At the simplest level, job search theory states that an individual's probability of gaining employment is equal to their probability of receiving a job offer multiplied by their probability of accepting it. A combination of both demand and supply side factors will therefore determine their duration of unemployment. It is generally thought that if there are high levels of long-term unemployment in an economy then it may be an indicator that 'structural unemployment' is present. This implies that long-term unemployment may be interpreted as a sign that the labour market is not functioning efficiently in terms of matching individuals to jobs as a result of changes in the demand or supply of labour in the economy.

Policy makers, analysts and individuals may be interested in the results of analysis based on durations of unemployment because changes in economic conditions do not affect all individuals identically. Further to this, there are thought to be social costs to unemployment (for example, it may be that there is some relationship between rising unemployment and rising crime). Long (2009) finds that an individual is less likely to be reemployed as the length of an individual's 
unemployment duration increases. This may be caused by a loss of attachment to the labour market and may be interpreted such that individuals should be encouraged to maintain contact with the labour market to increase their probability of finding employment.

\section{Description of Labour Force Survey data}

The first part of this article uses data from the LFS dataset. The LFS is a household survey which is weighted to provide information that is representative of the UK population. It collects information on a range of labour force characteristics and related topics. The LFS is collected on a quarterly basis and was originally designed to produce crosssectional data to facilitate the production of official labour market statistics.

The LFS is conducted using rolling five quarter waves, with each sample household retained for five consecutive quarters, and a fifth of the sample replaced each quarter. The ability to track an individual across quarters produces a rich source of longitudinal data, so ONS made the LFS longitudinal dataset available to the public in 1992.

The sample used for this section of the article spans the period Q3 (July to September) 2006 to Q4 (October to December) 2009. This study has restricted the data to analyse respondents aged 18 to state pension age (59 for women and 64 for men for that time period). The model does not include 16 to 18 year olds because there are several economic and non-economic reasons why respondents in this age group may move in and out of economic activity (predominantly educational reasons) making modelling unreliable. Also education policies have changed over the sample timeframe meaning that consistency may be lost when trying to track these individuals' economic statuses over time.
The definitions of employment and unemployment for the first part of this article are consistent with those used by both ONS to calculate official UK rates and levels, and also with the International Labour Organisation (ILO) definitions of these indicators ${ }^{2}$. A person is considered to be unemployed if they:

- are without a job, want a job, have actively sought work in the last four weeks, and are able to start work within the next two weeks. Or

- are out of work, have found a job and are waiting to start it in the next two weeks

A person is considered to be employed if they:

- are in paid employment at work for at least one hour over the reference week (or temporarily not at work during the reference period but have a formal attachment to their job). Or

- are in self-employment at work for at least one hour over the reference week (or is a person with an enterprise who is temporarily not at work during the reference period for any specific reason)

Finally the economically inactive group consists of:

- those people who are out of work but who do not satisfy all of the ILO criteria for unemployment. This is often because they are either not seeking work or are unavailable to start work

In this section of the study an individual is identified as having a spell of unemployment in two instances: firstly, if they report being unemployed in their first interview upon entering the sample then they are asked 'Which week, month and year did you leave your last paid job?'. By combining the responses of this question with the reference date of the interview, the length of time (in weeks) that the respondent has been unemployed for may be derived. Secondly, if a respondent is made unemployed during any of the remaining four quarters that they are in the sample, then they are given a spell which increases by three months for each subsequent quarter that they report being unemployed.

The economic destination from unemployment is calculated from respondents' reported statuses in the labour market. For example, if a respondent enters the sample unemployed and finds employment within the five quarter period of that sample then their spell is categorised as ending in employment (likewise with inactivity). If a respondent remains unemployed for the entire sample then they are categorised as not ending their spell.

Each observation in the longitudinal dataset has an associated weighting factor which serves two purposes. Firstly, the weights allow the sampled data to produce estimates for the level of the UK population. Secondly, they compensate for non-response and attrition bias. Thus, all results presented in this section of the article have been weighted using ONS weights (based to the 2009 population).

\section{Modelling methods}

When using econometric modelling to explain or predict phenomenon based on individuals, it is important to consider the structure of the sample. Taking unemployment as an example, an analyst may be interested in studying the effect that the duration of unemployment has on an individual's likelihood of returning to work. However, only a sub-sample of the sample will have a

\section{Box 1}

\section{Descriptive statistics of LFS data}

A preliminary overview of the data reveals that, in the period from Q3 2006 to Q4 2009, the weighted total count of respondents was $384,917,000$. Twelve per cent of these either entered the sample unemployed or experienced unemployment during the five quarters that they were interviewed. This means that there were $44,805,000$ individuals with a spell of unemployment. The mean length of such an unemployment spell was 8.8 months.
Of the $44,805,000$ individuals found to have an unemployment spell:

- $17,426,000$ (39 per cent) ended their spell into employment during the sample period

- $12,239,000$ (27 per cent) ended their spell into inactivity during the sample period

- 15,526,000 (35 per cent) remained unemployed

- it should be noted that these figures do not add exactly up to 100 per cent. This is because a small number of individuals were found to have more than one spell 
Table 1

\section{Base categories for LFS modelling}

\begin{tabular}{ll}
\hline Characteristic & Base category \\
\hline Age & 35 through 49 \\
Sex & Female \\
Ethnicity & Not classified as an ethnic minority \\
Marital status & Unmarried with no dependent children \\
Education & Below GCSE \\
Housing & Renting privately \\
Region & 'West Midlands Metropolitan County' \\
Previous occupation & 'Elementary' \\
\hline
\end{tabular}

Source: Labour Force Survey

Table 2

Personal characteristics and the probability of having a spell of unemployment

\begin{tabular}{lrr}
\hline & Marginal effect ${ }^{1}$ & Statistical significance $^{2,3}$ \\
\hline Age 18 through 24 & 4.5 & $* * *$ \\
Age 25 through 34 & -1.1 & $* * *$ \\
Age 50 through 59 & -2.0 & $* * *$ \\
Age 60 plus & -4.5 & $* * *$ \\
Male & 3.2 & $* * *$ \\
Ethnic minority & 4.6 & $* * *$ \\
Married & -5.5 & $* * *$ \\
Dependent child and female & 2.2 & $* * *$ \\
GCSE & & $* *$ \\
\hline
\end{tabular}

\section{Notes:}

Source: Authors' calculations

1 Marginal effects may be interpreted as percentage point changes (relative to the reference category as set out in Table 1).

2 Only statistically significant results are shown. Please contact author for full outputs.

$3 * * *$ Denotes significance at the 1 per cent level, ** Denotes significance at the 5 per cent level,

* Denotes significance at the 10 per cent level.

spell of unemployment at all. It would be incorrect to simply select the subsample of individuals who have a spell of unemployment and conduct analysis on them. The reason for this is that there may be some underlying characteristics that bias these individuals to be unemployed in the first place. Analysis must be conducted to investigate the likelihood of an individual being unemployed and any bias corrected.

The first half of this article, therefore, uses a 'Heckman selection' model introduced by Heckman $(1976,1979)$ (sometimes called the two-stage-method) which adjusts for any bias potentially introduced through the use of a subsample. An explanation of the Heckman selection model may be found in

\section{Technical Note 1 .}

Once the selection effects have been adjusted for, analysis may be run on the data to distinguish the characteristics which affect the duration of unemployment. Finally the model can estimate the effects of individual characteristics and the length of unemployment have on whether an individual finds employment.

\section{Modelling the likelihood of having a spell of unemployment}

Before modelling the effect that a spell of unemployment has on the probability of a individual entering employment, it is pertinent to consider if there are any characteristics that make the individual more (or less) likely to be unemployed in the first place. Using the Heckman approach outlined before, the selection model is a probit model that estimates the probability of having an unemployment spell. The probability is modelled as a function of:

- Age

- Sex

- Ethnicity

- Marital status

- Housing tenure

- Having dependent children in the household

- Education level

- Previous occupation

- Region

- Date of interview

When presenting the results of the selection model; marginal effects are shown. This means that the interpretation of the model is relatively simple. The marginal effect represents the percentage point change in the probability of having a spell of unemployment following a change in one of the explanatory variables. In this case they represent percentage point changes compared to the base category (as defined in Table 1).

For example, Table 2 shows that an individual aged between 18 and 25 years old is 4.5 percentage points more likely to have an unemployment spell then an individual aged 35 to 49 years old. Similarly, a married individual is 5.5 percentage points less likely to experience a spell of unemployment than an individual who is not married.

\section{Results - modelling the probability of having a spell of unemployment}

\section{Personal characteristics}

Table 2 shows that age is found to have a varied effect on the probability of having an unemployment spell coming into the sample (or during the sample period). The age group found to have the highest probability of having an unemployment spell is the youngest group (aged 18 through 24). Second highest is the control group (35 through 49) with all other age groups reporting lower probabilities than these. All other things being held equal; men are 3.2 percentage points more likely to have an unemployment spell than women. There is no statistically significant impact attached to being male and having a dependent child, however women with one or more dependent children are 2.2 percentage points more likely to have an unemployment spell. Similarly, individuals who report belonging to an ethnic minority are more likely to have a spell of unemployment by 4.6 percentage points relative to the base category.

Education appears to have little effect on the probability of coming into the sample unemployed (or experiencing unemployment during the sample period). When compared to individuals who report 'below GCSE' levels of education, it is only those with GCSEs where any statistical significance is found. Perhaps unexpectedly, individuals with GCSEs are found to be more likely to have a spell of unemployment, albeit that the marginal effect is less than one percentage point. The small size of the coefficient suggests that this finding has relatively little impact 
Table 3

Housing and the probability of having a spell of unemployment

\begin{tabular}{lrr}
\hline & Marginal effect $^{1}$ & Statistical significance $^{2}$ \\
\hline Rent-free & -3.9 & $* * *$ \\
Own home & -1.8 & $* * *$ \\
Mortgage & -2.2 & $* * *$ \\
Housing Association & 3.4 & $* * *$ \\
\hline
\end{tabular}

\section{Notes:}

Source: Authors' calculations

1 Marginal effects may be interpreted as percentage point changes (relative to the reference category 'Renting privately' - not shown).

$2 * * *$ Denotes significance at the 1 per cent level, ** Denotes significance at the 5 per cent level, * Denotes significance at the 10 per cent level.

\section{Figure 1}

Region and the probability of having a spell of unemployment ${ }^{1,2}$

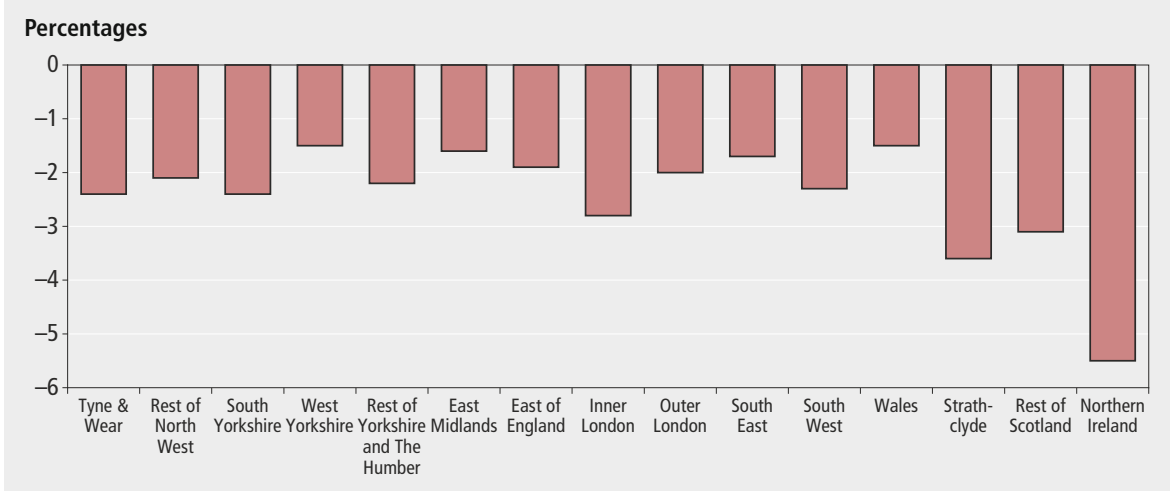

\section{Notes:}

Source: Authors' calculations

1 Marginal effects may be interpreted as percentage point changes (relative to the reference category 'West Midlands Metropolitan County' - not shown).

2 Only statistically significant results are shown. Please contact author for full outputs.

\section{Table 4}

\section{Occupation and the probability of having a spell of unemployment}

\begin{tabular}{lrr}
\hline & Marginal effect $^{1}$ & Statistical significance $^{2}$ \\
\hline Managers and senior officials & -7.0 & $* * *$ \\
Professional' & -7.8 & $* * *$ \\
Associate professional and technical & -6.9 & $* * *$ \\
Administrative and secretarial & -5.1 & $* * *$ \\
Skilled trades & -5.4 & $* * *$ \\
Personal service & -6.0 & $* * *$ \\
Sales and customer service & -4.0 & $* * *$ \\
Process, plant and machine & -3.9 & $* * *$ \\
\hline
\end{tabular}

\section{Notes:}

Source: Authors' calculations

1 Marginal effects may be interpreted as percentage point changes (relative to the reference category 'Elementary' - not shown).

$2 * * *$ Denotes significance at the 1 per cent level, ** Denotes significance at the 5 per cent level, * Denotes significance at the 10 per cent level.

on the probability of having a spell of unemployment (despite the unexpected direction of the effect).

\section{Housing and region}

Table 3 shows that the housing tenure an individual reports to reside in has a statistically significant relationship with the probability of having an unemployment spell. Living in Housing Association owned accommodation is associated with being 3.4 percentage points more likely to be unemployed when entering the sample (or becoming unemployed during the five quarters of the sample) when compared to renting privately. Interpretation of this result must be conducted with caution. It is unlikely to be the case that living in Housing Association property impacts an individual's employment prospects. It is more likely that there is a characteristic which is systematically shared by individuals who tend to reside in Housing Association properties. If some unquantifiable characteristic is, indeed, shared by such individuals then the 'Housing Association' variable would inadvertently pick up this effect. All other housing situations are associated with lower probabilities of having a spell: Owning a home outright (1.8 percentage points less likely), owning a home with a mortgage (2.2 percentage points less likely) and living rent free (3.9 percentage points less likely).

Figure 1 presents the marginal effects associated with the region an individual resides in. It shows that individuals residing in the control region ('West Midlands Metropolitan County') are found to have the highest probability of having a spell of unemployment. When compared to other regions, individuals residing in 'West Midlands Metropolitan County' are up to 5.5 percentage points more likely to have an unemployment spell (in this example when compared to 'Northern Ireland'). Interpretation of regional dummies is complex as they may be picking up the effects of the macro economy. For example, it is possible that Northern Ireland saw strong growth over the period analysed. The model makes no attempt to distinguish between these macro factors and whether the labour market is structurally different to the control region.

\section{Occupation}

Individuals who report their previous occupation to be the control occupation ('Elementary') are found to have the highest probability of having a spell of unemployment.

Table 4 shows that, when compared to other occupations, individuals who are in the 'Elementary' group are up to 7.8 percentage points more likely to have an unemployment spell (in this example when compared to 'Professional').

\section{Results - modelling the length of the unemployment spell} Results presented hereafter should always be interpreted with the findings of the selection model in mind. The first conditional model is an ordinary least squares (OLS) model which sets out to predict and model the length of the spell of unemployment given that a spell is experienced at all.

Table 5 summarises the statistically significant results of the OLS econometric model. It does not make any attempt to explain or predict the destination (in terms of economic status) from unemployment. A spell of unemployment is classified as 
Table 5

\section{Estimating the length of spell of unemployment (given that a spell is observed)}

\begin{tabular}{lrr}
\hline & Coefficient $^{1}$ & Statistical significance $^{2}$ \\
\hline Constant & 3.7 & $* *$ \\
Age 18 through 24 & -1.3 & $*$ \\
Age 50 through 59 & 2.1 & $* *$ \\
Male & & $* * *$ \\
Dependent child and male & 1.6 & $* * *$ \\
Job Seekers Allowance & 1.6 & $* * *$ \\
Administrative and secretarial & 3.8 & $*$ \\
Skilled trades & & $* *$ \\
Sales and customer service & 1.9 & $* *$ \\
Process, plant and machine & 2.3 & $* *$ \\
\hline
\end{tabular}

\section{Notes:}

Source: Authors' calculations

1 Only statistically significant results are shown. Please contact author for full outputs.

$2 * * *$ Denotes significance at the 1 per cent level, ** Denotes significance at the 5 per cent level, * Denotes significance at the 10 per cent level.

ending, for the purposes of this model, if an individual moves from unemployment to employment or inactivity.

\section{Personal characteristics}

The constant reported in Table 5 may be interpreted as the expected length of unemployment spell for an individual in all of the base categories (defined in Table 1). To that end, once such an individual becomes unemployed the expected length of unemployment is 3.7 months. Age is found to affect the expected length of unemployment with individuals in the youngest age group (18 through 24) expecting 1.3 fewer months and individuals in the older age group (50 though 59) expecting an additional 2.1 months of unemployment on average.

Males, on average, can expect to experience spells of unemployment which are shorter by 1.6 months (although it should be remembered that males are more likely to have a spell in the first place). A male with a dependent child in the household may expect a longer spell of unemployment (1.6 months longer on average) when compared to a female with no dependent children. The model finds no significant effect attached to having a dependent child for women when estimating the length of unemployment spell (although it should be remembered that women with a dependent child are more likely to experience an unemployment spell in the first place).

\section{Job Seekers Allowance}

The LFS asks respondents whether they claim unemployment related benefits. In this study the Job Seekers Allowance (JSA) variable is defined such that individuals are classified as claiming JSA if they report to claim:

- Contributory JSA and/or

- Income based JSA and/or

- JSA (type not stated) and/or

- National Insurance credits

This variable is not included in the selection model because there is a very strong relationship between being unemployed and claiming JSA. Clancy and Stam (2010) explain the relationship between unemployment and unemployment related benefits. The JSA variable would suffer from high correlation with the selection variable, however it may be an interesting variable to consider when looking at the effects on the length of an unemployment spell.

Table 5 reveals that an individual who reports to be claiming JSA may expect a longer spell of unemployment (an average of 3.8 months longer) than an individual who is not claiming JSA (all other things

\section{Table 6}

Duration of unemployment and the probability of leaving unemployment spell into employment (given that a spell is observed)

\begin{tabular}{lc}
\hline Spell length (months) & Marginal effect $^{1}$ \\
\hline 6 or less & Base \\
$7-12$ & -17.7 \\
$13-18$ & -27.2 \\
$19-24$ & -11.3 \\
$25-30$ & -21.0 \\
$37-42$ & -12.1 \\
$49-54$ & -24.3 \\
$60+$ & -10.5 \\
\hline
\end{tabular}

Notes:

Source: Authors' calculations

1 Marginal effects may be interpreted as percentage point changes (relative to the reference category '6 or less'). being equal). This study will return to the JSA variable to consider its effect on probability of finding employment later.

\section{Occupation}

Individuals attached to 'Administrative and Secretarial' 'Skilled Trades' 'Sales and Customer Service' and 'Process, Plant and Machine' may expect longer spells of unemployment. Attachment to any other occupational group does not appear to have any significant effect on the length of an individual's unemployment spell.

\section{Results - modelling the chance of finding employment}

The two models presented thus far have attempted to explain the probability of an individual becoming unemployed. The second model has attempted to explain the relationships between the characteristics of respondents and the expected length of that spell of unemployment (given that they are unemployed in the first place). The final model in this section runs a Heckman probit model on the LFS respondents to examine the relationships between (amongst other things) the duration of unemployment and the probability of ending that spell into employment. The model calculates the probability of the spell ending in employment during the five quarters for which the respondent was in the longitudinal sample.

\section{Duration of unemployment}

Once appropriate considerations have been made for sample selection bias, the duration of unemployment is found to have a significant effect on the probability of ending the unemployment spell into employment. The base length of unemployment is 'six months or less'. Individuals who have a longer spell of unemployment than the base have a lower probability of moving into employment 


\section{Figure 2}

Age and the probability of leaving unemployment spell into employment (given that a spell is observed) ${ }^{1}$

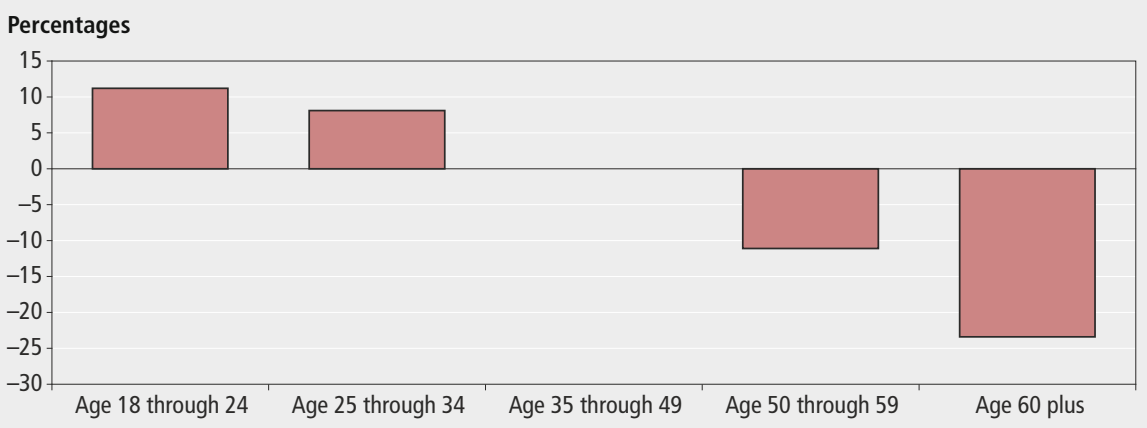

Notes:

Source: Authors' calculations

1 Marginal effects may be interpreted as percentage point changes (relative to the reference category 'age 35 through 49' which therefore has a marginal effect equal to zero).

Table 7

Personal characteristics and the probability of leaving unemployment spell into employment (given that a spell is observed)

\begin{tabular}{lrr}
\hline & Marginal effects $^{1}$ & Statistical significance $^{2,3}$ \\
\hline Male & -3.7 & $*$ \\
Married & 9.1 & $* * *$ \\
Dependent child and male & -1.7 & $*$ \\
Dependent child and female & -10.7 & $* * *$ \\
Job Seekers Allowance & 19.2 & $*$ \\
GCSE & 5.3 & $* * *$ \\
Further Education & 13.6 & $* * *$ \\
Degree & 12.1 & $* * *$ \\
\hline
\end{tabular}

Notes:

Source: Authors' calculations

1 Marginal effects may be interpreted as percentage point changes (relative to the reference category as set out in Table 1).

2 Only statistically significant results are shown. Please contact author for full outputs.

$3 * * *$ Denotes significance at the 1 per cent level, ** Denotes significance at the 5 per cent level, * Denotes significance at the 10 per cent level.

Table 6 outlines the effect that of the duration of unemployment on the probability that the unemployment spell ends in employment.

For example, an individual with an unemployment spell of between seven and twelve months is (on average) 17.7 percentage points less likely to end their spell in employment during the sample period than an identical individual with six months or less in unemployment.

Table 6 shows that the individuals who have the shortest duration of unemployment (six or less months) are most likely to find such employment (as every other category reduces the probability of such an outcome).

\section{Personal characteristics}

Figure 2 shows the marginal effects that age has on the probability of an unemployed individual finding employment when compared to individuals aged 35 to 49 . Age is found to have a negative effect on the probability of finding employment from a spell of unemployment. It can be seen that the youngest age group (age 18 to 25 ) are 34 percentage points more likely than the oldest age group ( 60 plus) to find employment during the sample period.

Table 7 summarises the effects of individual characteristics. All other things being held equal, unemployed men are 3.7 percentage points less likely to find employment in the sample period than unemployed women. Married individuals are 9.1 percentage points more likely than unmarried individuals to find employment.

Men with a dependent child in the household are 1.7 percentage points less likely to find employment when compared to women with no dependent children. Unemployed women with a dependent child are 11 percentage points less likely to find employment, compared to the same category.

Education appears to have a positive effect on the conditional probability of finding employment. When compared to individuals reporting a highest qualification of 'below GCSE', holding a GCSE or equivalent increases the probability of finding employment by 5.3 percentage points. This increases to 13 percentage points for individuals whose highest qualification is equivalent to a further education and to 12 percentage points for individuals with a degree. This is likely to be related to the demand for labour, that there is more demand from firms for higher skilled workers. This result alludes to a positive but diminishing effect in education's influence over the probability of finding re-employment.

\section{Other characteristics}

The JSA variable (as defined previously) is found again to be statistically significant. Individuals who report claiming JSA are 19 percentage points more likely to find employment during the sample period. There are several possible explanations for this, and competing theories around the effects of unemployment related benefits. It may be that the conditions connected with claiming JSA encourage unemployed individuals to remain 'attached' to the labour market. For example, to claim JSA an individual must attend an interview with a Jobcentre Plus adviser. Claimants of JSA have access to specialist help in finding vacancies, $\mathrm{CV}$ writing and interview skills and so $\mathrm{on}^{3}$. The positive effect associated with claiming JSA appears to support this view. Critics of unemployment benefit-related welfare programmes argue that such programmes provide disincentives for the unemployed to seek employment. It should be remembered from the previous model that individuals who claim JSA expect longer spells of unemployment by 3.8 months on average, perhaps lending support to such a hypothesis.

\section{Housing and region}

One housing category was found to be significantly related when modelling the conditional probability of finding employment. All other factors being equal, individuals who own a house with a mortgage are 6.3 percentage points more likely to find employment during the sample period (compared to individuals who rent privately). This may reflect a labour supply effect; that individuals who are committed to paying a mortgage may be more intensive in their job search and more willing to accept work in order to maintain mortgage payments.

It can be seen in Figure 3 that the region an individual lives also influences the conditional probability of finding employment during the sample period, with each region having a positive effect 


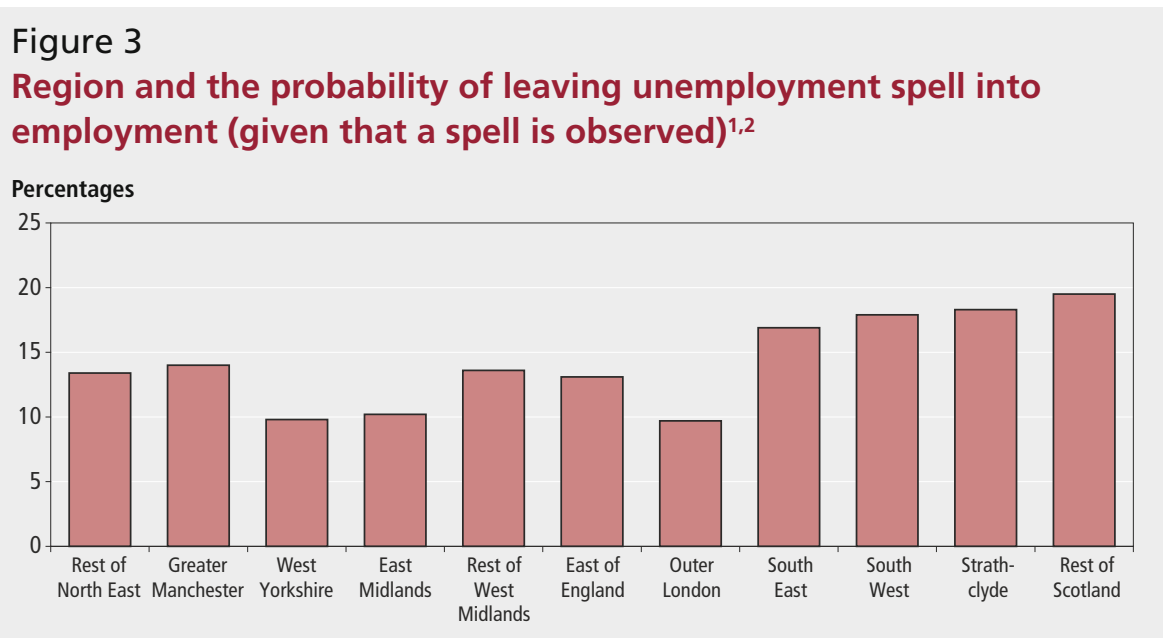

Notes:

Source: Authors' calculations

1 Marginal effects may be interpreted as percentage point changes (relative to the reference category 'West Midlands Metropolitan County' - not shown).

2 Only statistically significant results are shown. Please contact author for full outputs.

Table 8

Occupation and the probability of leaving unemployment spell into employment (given that a spell is observed)

\begin{tabular}{lcc}
\hline & Marginal Effects $^{1}$ & Statistical Significance $^{2}$ \\
\hline Managers and senior officials & 10.3 & $* * *$ \\
Professional & 12.4 & $* * *$ \\
Associate professional and technical & 10.1 & $* * *$ \\
Administrative and secretarial & 6.8 & $* * *$ \\
Skilled trades & 7.4 & $* * *$ \\
Personal service & 8.7 & $* * *$ \\
Sales and customer service & 5.2 & $* * *$ \\
Process, plant and machine & 5.1 & $* * *$ \\
\hline
\end{tabular}

\section{Notes:}

Source: Authors' calculations

1 Marginal effects may be interpreted as percentage point changes (relative to the reference category 'Elementary' - not shown).

$2 * * *$ Denotes significance at the 1 per cent level, ** Denotes significance at the 5 per cent level,

* Denotes significance at the 10 per cent level.

when compared to the base region ('West Midlands Metropolitan County').

\section{Occupation}

Table 8 shows that the base occupation ('Elementary') is found to have the lowest probability of finding employment. The occupation with the highest probability of finding employment from a spell of unemployment is 'Professional'. Individuals in this occupation are 12 percentage points more likely to find employment when compared to individuals in the 'Elementary' occupation (all other factors remaining equal). This occupation is closely followed by 'Managers and Senior Officials' and 'Associate Professional and Technical' both of which are both 10 percentage points more likely to find employment during the sample period when compared to the base category.

The Heckman probit analysis has been informative about factors affecting both the probability of entering unemployment and the probability of exiting unemployment into employment. However, it does not tell us anything about exiting to the state of inactivity. The remainder of this article develops a model which takes account of the conditional probability of exit to inactivity as well as employment.

\section{The competing risks econometric model}

To account for multiple destinations of exit from unemployment (that is, from movements into inactivity or employment), an independent competing risks model is estimated. A technical explanation of the competing risks model is given in Technical Note $\mathbf{2}$. To fit an OLS model to these data is not appropriate because the censored spells would cause bias. The duration model framework controls for such censoring. An unemployed person can either remain in unemployment, exit to employment or exit to inactivity. The competing risks model estimates the probability of an individual leaving unemployment at a specific time to a given destination, conditional on their elapsed duration of unemployment. This is different from the single risk approach that is used in Long (2009) because it takes account of the destination of exit.

The hazard function, which is assumed to take the proportional hazards form, calculates the probability of an individual exiting from the state of unemployment conditional on the elapsed duration of their unemployment spell. Due to the proportional hazards form, the estimated coefficients may be interpreted as the logged effect that a variable has upon the probability of exiting unemployment to employment (or unemployment to inactivity) relative to the reference category.

The single risk model of Long (2009) controls for unobserved differences between individuals (also known as unobserved heterogeneity). Lancaster (1979) shows that ignored unobserved heterogeneity can bias not only the pattern of duration dependence but also the estimated coefficients of the explanatory variables. However, generalisation of the treatment of unobserved heterogeneity to a competing risks framework requires strong assumptions about the correlation of the disturbance term across destination specific hazards. As Naredranathan and Stewart (1993) point out, the distortions which may arise from techniques to account for unobserved heterogeneity may actually be more severe than the bias resulting from ignored unobserved heterogeneity in the first place. To that end it is more appropriate for the competing risk model not to control for the unobserved heterogeneity.

To test whether the hazard of exit to the different destinations is behaviourally distinct, the likelihood ratio test of Naredranathan and Stewart (1991) is implemented. This test describes if it is appropriate to estimate a single risk model of the hazard of exit from unemployment, without distinguishing between different exit destinations. The null of incidental hazards of exit to employment and inactivity is strongly rejected at the 1 per cent significance level. Thus the competing risks estimation of exit probabilities (and results presented hereafter) is therefore valid and appropriate.

\section{The British Household Panel Survey data}

The data used in this analysis is a subsample of individuals drawn from the 


\section{Table 9}

\section{Base categories for BHPS modelling}

\begin{tabular}{ll}
\hline Characteristic & Base category \\
\hline Age & 35 through 49 \\
Sex & Male \\
Ethnicity & White \\
Marital status & Single with no children \\
Education & No qualifications \\
Housing & Privately rented accommodation \\
Region & South East of England \\
\hline
\end{tabular}

Source: British Household Panel Survey

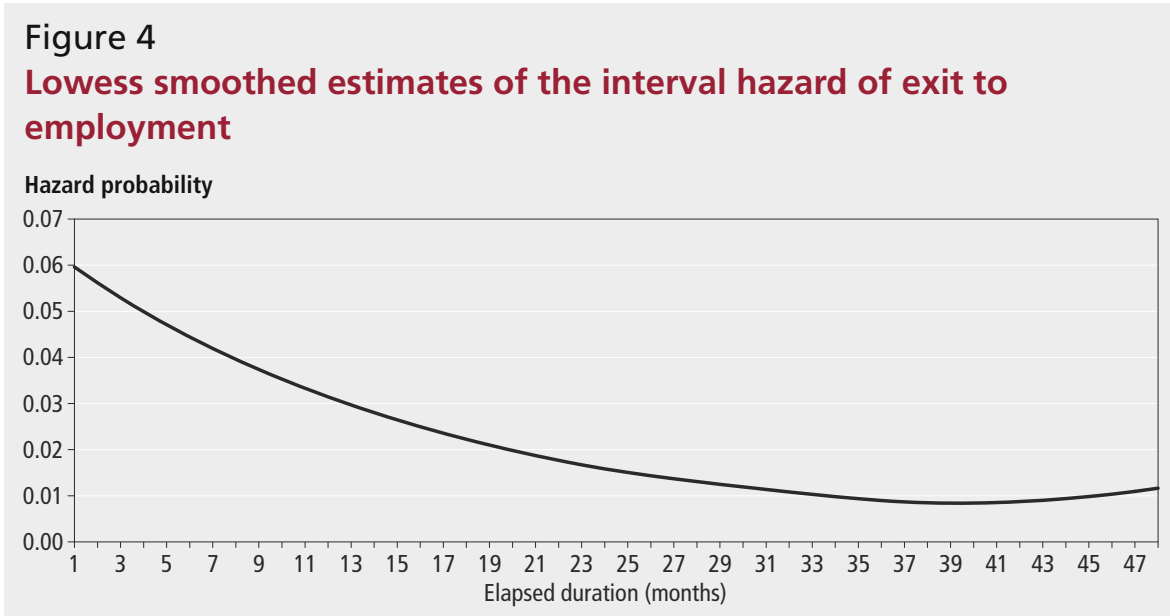

Source: Authors' calculations

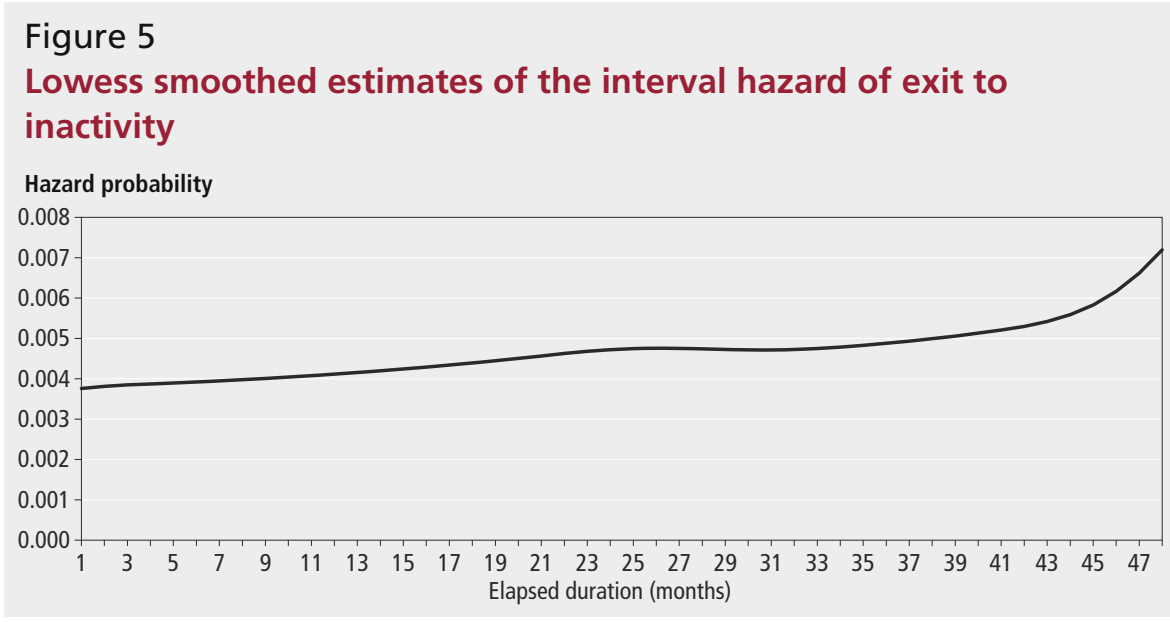

Source: Authors' calculations

British Household Panel Survey (BHPS) ${ }^{4}$. This is a nationally representative survey of approximately 10,000 households, comprising 17 waves of information at both the household and individual level. For more information on this survey see Taylor et al (2009). The sample used in this section comprises information on the unemployment spells of 1,836 individuals over the period April 2001 to 2006. The BHPS is a rich data source, however it is a survey and is therefore subject to the usual weaknesses of survey data such as recall and self classification error. It is also important to note that the definitions of unemployment and inactivity used in this study are not consistent with International Labour Organisation (ILO) definitions.

A flow sample selection is used, so that an individual enters the sample when they become unemployed and remain in the sample until they exit to employment, inactivity or leave the BHPS altogether. Similar to the Heckman analysis conducted in the first part of this article, the results should be interpreted by comparing the probabilities relative to a control individual. For the competing risk model the control individual has the characteristics outlined in Table 9.

\section{Results - the underlying conditional probability of exiting unemployment}

\section{Duration of unemployment}

Figure 4 plots a smoothed version of the estimated interval hazard of exit to employment ${ }^{5}$. The probability of an individual finding employment decreases as the length of their unemployment spell increases. This result is consistent with the idea of individuals losing skills and attachment with the labour market as their unemployment spells lengthen, or with employers attaching stigma to potential employees who have a longer unemployment spell.

Figure 5 plots a smoothed version of the estimated interval hazard of exit to inactivity ${ }^{5}$. It shows that the probability of an individual exiting unemployment into inactivity increases as the duration of unemployment increases. It can be seen, however, that the conditional probability of exit appears to be relatively constant for the first eighteen months of a spell and is increasing thereafter. This may suggest that there is some sort of threshold effect around a year and a half into an unemployment spell. This may be related to the benefit structure or to individuals becoming 'discouraged'. A discouraged worker is an individual who wants to work but is not looking for a job because of a perceived lack of demand.

\section{Results - simulating the destination from unemployment}

To get a clearer indication of the effect that each variable has on the hazard of exiting to unemployment or to inactivity, the probability of exit to each destination conditional on an exit occurring at a specific time is simulated. Table $\mathbf{1 0}$ simulates the probabilities of an individual exiting unemployment after 3, 9, 15, and 21 months unemployment. It essentially presents the net effect of characteristics relative to the reference person.

Table 10 shows that age significantly affects the destination from unemployment. An individual in the youngest age group (18 to 24 ) is more likely to exit to inactivity. Being aged 25 to 34 increases the probability of exiting into employment (relative to an identical individual aged 34 to 49 ).

Being married is not found to have a significant effect on exit probabilities in the competing risks model. However, an individual with a spouse in employment 
Table 10

Results of the simulation: probability of exit to employment or inactivity

Percentage change (relative to the control individual)

\begin{tabular}{|c|c|c|c|c|c|c|c|c|}
\hline & \multicolumn{4}{|c|}{ Exit to inactivity after: } & \multicolumn{4}{|c|}{ Exit to employment after: } \\
\hline & 3 months & 9 months & 15 months & 21 months & 3 months & 9 months & 15 months & 21 months \\
\hline Claiming JSA & 29.1 & 26.9 & 25.7 & 22.6 & -1.9 & -3.9 & -4.9 & -7.3 \\
\hline Spouse in Employment & -26.0 & -25.2 & -24.6 & -22.8 & 1.77 & 3.7 & 4.7 & 7.4 \\
\hline Owns Home with Mortgage & -11.8 & -11.8 & -11.6 & -10.7 & 0.9 & 1.7 & 2.2 & 3.5 \\
\hline Aged 18 to 24 & 15.2 & 13.3 & 12.6 & 11.1 & -1.0 & -2.0 & -2.4 & -3.6 \\
\hline Age 25 to 34 & -18.7 & -17.8 & -17.3 & 5.2 & 1.2 & 2.6 & 3.3 & 5.2 \\
\hline GCSE & -19.9 & -19.4 & -19.0 & -17.5 & 1.3 & 2.8 & 3.6 & 5.7 \\
\hline A Level & -15.8 & -15.6 & -15.3 & -14.1 & 1.1 & 2.3 & 2.9 & 4.6 \\
\hline Degree & -7.2 & -7.9 & -7.9 & -7.4 & 0.5 & 1.2 & 1.5 & 2.4 \\
\hline Higher & -48.4 & -47.2 & -46.4 & -43.9 & 3.2 & 6.9 & 8.9 & 14.2 \\
\hline
\end{tabular}

Source: Authors' calculations

is more likely to exit into employment (relative to a single individual).

Owning a home with a mortgage is found to be significantly related to the probability of exit to employment, relative to an individual renting privately. The result is consistent with the LFS findings of the Heckman model presented earlier in this article and may reflect supply side forces acting on an individual's job search intensity. The competing risks model also suggests that there is a regional effect to re-employment prospects. An individual residing in Scotland, Wales or Northern Ireland is more likely to exit to inactivity than an identical individual residing in the South East of England, possibly reflecting regional disparities in labour force demand in the UK economy.

Claiming JSA appears to reduce an individual's probability of exit to employment, relative to the reference individual. This result is consistent with the negative replacement ratio effect found in Long (2009) using the same dataset, and alluded to in the Heckman model presented earlier in this article (which found that that LFS respondents who claim JSA tend to experience longer spells of unemployment).

Having GCSEs, 'A' Levels, a Higher Educational Qualification or a Degree increases an individual's probability of exiting unemployment into employment (relative to an identical individual with no qualifications). This is may reflect demand side factors, with employers preferring highly skilled employees to those with no qualifications. Interestingly, leaving aside the positive impact of having either a GCSE, ' $\mathrm{A}$ ' Level, 'Higher Education' or Degree on exit to employment appears, again, to diminish with the level of education (supporting the results of the LFS Heckman probit model).

\section{Conclusion}

This article has studied the effects that the length of time an individual is unemployed for has on the expected exit from unemployment. It has taken two approaches; applying a Heckman two stage model to Labour Force Survey data and a competing risks model to the British Household Panel Survey. It set out to test consistency between the LFS and BHPS datasets and has presented results from both data sources which largely support each other, despite differences in methodologies.

The article has analysed how the length of an individual's spell of unemployment affects the probability of re-employment or entering inactivity. Both the LFS and BHPS models in this article broadly support the previous findings of Long (2009), that an individual is less likely to leave unemployment via employment as the length of the unemployment spell increases. This finding is ramified using the competing risks model, which indicates that an individual is actually more likely to leave unemployment via inactivity as the spell of unemployment lengthens.

The results of this article have found that there are identifiable characteristics which make people more or less likely to a) suffer from unemployment and b) experience longer spells of unemployment. Preliminary modelling on the LFS data suggests that men are more likely to experience unemployment than women. However, they can expect a shorter spell of unemployment (all other things being equal). The same model suggests that an individual living in Housing Association accommodation has a higher probability of experiencing unemployment (all other things being equal). This must be interpreted with caution as this indicator may be picking up some other (unquantifiable) characteristic systematically common amongst such individuals, rather than being evidence of a negative impact of
Housing Association policy. Education has a positive, but diminishing, effect on the probability of moving from unemployment to employment. Finally, both models indicate that that owning your home with a mortgage is significantly related to the probability of finding employment after having a spell of unemployment.

\section{Notes}

1. The most recent Labour Market Statistical Bulletin can be found at: www.statistics.gov.uk/StatBase/ Product.asp?vlnk=1944

2. For more information see: www.ilo.org/global/What_we_do/ Statistics/topics/Employment/lang-en/index.htm

3. More information about the conditions of JSA can be found at: www.direct.gov.uk/en/ MoneyTaxAndBenefits/ BenefitsTaxCreditsAndOtherSupport

4. The data used in this section of the publication were made available through the ESRC Data Archive. The data were originally collected by the ESRC Research Centre on Microsocial Change at the University of Essex (now incorporated within the Institute for Social and Economic Research). Neither the original collectors of the data nor the Archive bear any responsibility for the analyses or interpretations presented here.

5. For more information on the Lowess smoothing technique used in Figure 4 and Figure 5 see the STATA technical bulletin: http:// econpapers.repec.org/article/tsjstbull/ y_3a1992_3av_3a1_3ai_3a3_3agr6. htm 


\section{REFERENCES}

Clancy G and Stam P (2010) 'Explaining the difference between unemployment and the claimant count', Economic\& Labour Market Review, Vol 4, No 7, pp 21-27

Heckman J (1976) 'The Common Structure of statistical models of truncation, sample selection and limited dependent variables and a simple estimator for such models', Annals of Economic Social Measurement 5(4), pp 475-492

Heckman J (1979) 'Sample selection bias as a specification error', Econometrica 47(1), pp 53-161

Lancaster T (1979) 'Econometric methods for the duration of unemployment',

Econometrica 47(4), pp 940-956

Long K (2009) 'Unemployment durations: Evidence from the British Household Panel Survey', Economic \& Labour Market Review Vol 3 No 10, pp 48-54
Narendranathan W and Stewart B (1991)

'Simple methods for testing for the proportionality of cause-specific hazards in competing risks models', Oxford Bulletin of Economics and Statistics 53(3), pp 331340

Narendranathan W and Stewart B (1993) 'Modelling the probability of leaving unemployment: Competing Risks Models with Flexible Base-Line Hazards', Journal of the Royal Statistical Society Series C 42(1), pp 65-83

ONS (2008) 'Duration of Unemployment', available from:

www.ons.gov.uk/about-statistics/ user-guidance/lm-guide/concepts/ unemployment/duration/index.html

Taylor M (ed) Brice, J, Buck N and PrenticeLane E (2009) 'British Household Panel Survey User Manual Volume A: Introduction, Technical Report and Appendices'. University of Essex: Colchester
Thomas J (1996) 'On the interpretation of covariate estimates in independent competing risks models', Bulletin of Economic Research 48(1), pp 27-29 


\section{TECHNICAL NOTE 1}

\section{The Heckman selection model}

This article makes use of the Heckman procedure (Heckman, 1976, 1979) to remove any sample selection bias. As explained in the main text of the article, if an analyst simply applied an Ordinary Least Squares (OLS) model on the data presented in this article it may result in biased parameter estimates. To simply regress $y$ on $X \beta$ (where $y$ is the length of unemployment spell and $X$ is a matrix containing information on several explanatory variables, as discussed in the text) would take no account of the selection process. There essentially exists a missing variable:

$\lambda\left(\frac{0-u}{\sigma}\right)$

It is necessary to take account of this by running the Heckman procedure. The procedure has two stages.

The first stage (selection model) estimates the probability of an individual having an unemployment spell, given the demographic (and other) characteristics. This is done using a variable $(Z)$ which takes the value ' 1 ' if the individual becomes unemployed and ' 0 ' if they do not. A probit model is run to estimate the probability that $Z={ }^{\prime}{ }^{\prime} 1, Z=w \delta+v$ (where $w=$ the characteristics of the individual and $v$ represents a term to take account of non-systematic errors in the model).

The results are used to calculate $\hat{\lambda}\left(\alpha_{i}\right)$ (the Inverse Mills Ratio) for each observation, which is then incorporated into the second stage equation (conditional model). The second stage equation is run on the selected sub-sample to make estimations of the specified explanatory variable.

$y=X \beta+\rho \sigma \lambda\left(\frac{0-u_{i}}{\sigma}\right)$ or $y=X \beta+\rho \sigma \hat{\lambda}$

The conditional model counters any bias from the condition that not every individual has an unemployment spell at all.

\section{TECHNICAL NOTE 2}

\section{Competing risks model}

The overall discrete time interval hazard, denoted $h(j)$, gives us the hazard of exit from unemployment to either employment or inactivity. This can be written as:

$h(j)=\frac{S\left(a_{j-1}\right)-S\left(a_{j}\right)}{S\left(a_{j-1}\right)}$

where $S\left(a_{j}\right)$, the survivor function, denotes the probability of staying in unemployment until time $j$. The hazard is given by:

$h(j)=1-\exp \left(-\int_{a_{j-1}}^{a_{j}}\left[\theta_{A}(t)+\theta_{B}(t)\right] d t\right)$

where $\theta_{A}(t)$ and $\theta_{B}(t)$ represent the instantaneous hazard of exit to employment and inactivity, respectively. This equates to $h(j)=1-\left[\left(1-h_{A}(j)\right)\left(1-h_{B}(j)\right)\right]$ and implies that the overall survivor function is given by $S(j)=S_{A}(j) S_{B}(j)$

It follows from this that the destination specific interval hazards are given by

$h_{A}(j)=1-\exp \left(-\int_{a_{j}-1}^{a_{j}} \theta_{A}(t) d t\right)$ and $h_{B}(j)=1-\exp \left(-\int_{a_{j}-1}^{a_{j}} \theta_{B}(t) d t\right)$

For right censored cases the likelihood contribution is given by the probability of survival in both states until interval $j$ which is simply:

$L^{C}=S_{A}(j) S_{B}(j)$

$=\Pi_{k=1}^{J}\left[1-h_{A}(k)\right]\left[1-h_{B}(k)\right]$

The likelihood contribution for the case of exit to employment is given by:

$L^{A}=\operatorname{Pr}\left(a_{j-1}<T_{A} \leq a_{j}, T_{B}>T_{A}\right)$ 
$=\int_{a_{j}-1}^{a_{j}} \int_{i}^{\infty} f_{A}(u) f_{B}(v) d v d u$

If we assume transitions only occur at the interval boundaries, this simplifies to:

$L^{A}=\int_{a_{j-1}}^{a_{j}} f_{A}(u) d u \int_{a_{j}}^{\infty} f_{B}(v) d v$

$=\left[F_{A}\left(a_{j}\right)-F_{A}\left(a_{j-1}\right)\right]\left[1-F_{B}\left(a_{j}\right)\right]$

$=\left[\frac{h_{A}(j)}{1-h_{A}(j)}\right] S_{A}(j) S_{B}(j)$

The likelihood contribution for the case of exit to inactivity follows from this and the overall likelihood function is therefore:

$L=\left(L^{A}\right)^{\delta_{A}}+\left(L^{B}\right)^{\delta_{B}}+\left(L^{C}\right)^{1-\delta_{A}-\delta_{B}}$

$=\left[\frac{h_{A}(j)}{1-h_{A}(j-1)}\right]^{\delta_{A}} S_{A}(j)+\left[\frac{h_{B}(j)}{1-h_{B}(j-1)}\right]^{\delta_{B}} S_{B}(j)$

This equates to an additive separability in the log likelihood into parameters which are a function of only destination specific hazards.

It should be noted that, as in Naredranathan and Stewart (1993), the hazard of exit to employment is of primary interest in this analysis (Table A1). The hazard of exit to inactivity is less precisely estimated (Table A2).

\section{Table A1}

Statistically significant estimation results for the latent hazard of exit to employment

Coefficient $^{1}$

Standard Error ${ }^{2}$

Elapsed Duration (months):

Elapsed Duration $<7$

$6<$ Elapsed Duration $<13$

$12<$ Elapsed Duration $<19$

$18<$ Elapsed Duration $<25$

$24<$ Elapsed Duration $<31$

$30<$ Elapsed Duration < 37

$36<$ Elapsed Duration $<43$

$42<$ Elapsed Duration < 49

$54<$ Elapsed Duration < 61

Aged 18 to 24

Aged 25 to 34

$0.059^{* *}$

$0.029 * *$

0.021 **

$0.015^{* *}$

$0.012^{* *}$

$0.012^{* *}$

$0.007^{* *}$

$0.004^{* *}$

$0.036^{* *}$

$1.429 * *$

$1.220^{* *}$

Claiming JSA

$0.755^{* *}$

Spouse Works

$1.618^{* *}$

Highest Educational Attainment: GCSE

$1.547^{* *}$

Highest Educational Attainment: A Level

1.621 **

Highest Educational Attainment: Higher Education

Highest Educational Attainment: Degree

$1.923^{* *}$

1.950 **

Owns Home Outright

$1.489 *$ *

Owns Home with Mortgage

Region of Residence: Wales

Region of Residence: Scotland

1.639 * *

$0.742^{* *}$

0.730 **

$0.345^{* *}$

Notes:

$1 \%$ level, * Denotes

Exponentiated coefficients
significance at the $5 \%$ level.

2 Only statistically significant results are shown. Please contact the author for full outputs. 
Table A2

Statistically significant estimation results for the latent hazard of exit to inactivity

\begin{tabular}{|c|c|c|}
\hline & Coefficient $^{1}$ & Standard Error ${ }^{2}$ \\
\hline \multicolumn{3}{|l|}{ Elapsed Duration (months): } \\
\hline Elapsed Duration $<7$ & $0.004^{* *}$ & 0.286 \\
\hline $6<$ Elapsed Duration $<13$ & $0.004^{* *}$ & 0.299 \\
\hline $12<$ Elapsed Duration $<19$ & $0.004^{* *}$ & 0.326 \\
\hline $18<$ Elapsed Duration $<25$ & $0.005 * *$ & 0.347 \\
\hline $24<$ Elapsed Duration $<31$ & $0.005^{* *}$ & 0.389 \\
\hline $30<$ Elapsed Duration $<37$ & $0.006^{* *}$ & 0.397 \\
\hline $36<$ Elapsed Duration $<43$ & $0.002^{* *}$ & 0.634 \\
\hline $42<$ Elapsed Duration $<49$ & $0.007^{* *}$ & 0.490 \\
\hline $48<$ Elapsed Duration $<55$ & $0.002 * *$ & 1.038 \\
\hline $54<$ Elapsed Duration $<61$ & 0.004 & 0.286 \\
\hline Aged 18-24 & $1.644^{* *}$ & 0.184 \\
\hline Female & $1.917^{* *}$ & 0.133 \\
\hline Member of Ethnic Minority & $1.868^{*}$ & 0.254 \\
\hline Highest Education Attainment: Degree & $0.937^{*}$ & 0.214 \\
\hline Region of Residence: Scotland & $1.707^{*}$ & 0.253 \\
\hline Region of Residence: South West & $1.966 * *$ & 0.370 \\
\hline \multicolumn{3}{|l|}{ Notes: } \\
\hline \multicolumn{3}{|c|}{$\begin{array}{l}1 \text { Exponentiated coefficients are reported. ** Denotes significance at the } 1 \% \text { level, * Denotes } \\
\text { significance at the } 5 \% \text { level. }\end{array}$} \\
\hline
\end{tabular}

